\title{
ARTÍCULOS
}

ENRIQUE CIPRIANI stos lineamientos hechos acerca de la 17. Docencia Médica, por el carácter de mi 9. formación personal, intuyo que puede ser 112 aplicables a otras ramas del saber.

Se debe remarcar que el concepto de democracia a una universidad es válido sobre la base de niveles semejantes de información; lo demás no es sino una dictadura impuesta a nuestros actuales alumnos y futuros sucesores.

Ortega y Gasset define “... en la clase intelectual reside vagamente la única posibilidad de constituir una minoría selecta, capaz de influir hondamente en los destinos étnicos y dar un comienzo de una nueva organización a este pueblo nuestro (con referencia a España en 1922) que se deshace y atomiza cada día" "... lo importante en la vida es tener que hacer, una empresa, una tarea. Como sugiere Cervantes es más sabroso el camino que la posada".

"...la inteligencia no es una cosa que se tiene, sino una cosa que se es. No consiste en un instrumento externo que se maneja a voluntad, sino una delicadísima actividad localizada en el más radical centro de la persona".

La universidad significa el lugar en donde se estudia el conjunto de las cosas creadas. El mundo.

La universidad implica conocer lo que es la calidad universal. Estas acepciones son tomadas del diccionario de la Real Academia de Lengua Española.

En contraste con estas definiciones, nos encontramos con qué técnica esta definida como el conjunto de procedimientos y de cursos de que se sirve una ciencia o un arte. Significa la pericia o habilidad para usar de esos procedimientos y recursos.

En tanto que esas acepciones son tomadas del diccionario de la Real Academia de Lengua Española, el filósofo Abbagnano define lo universal como la

\section{REFORMULANDO LA DOCENCIA MÉDICA}

posibilidad de un juicio válido para todos los seres racionales. La ciencia está sólo en lo universal. El universal es la forma o sustancia de las cosas.

Es necesario que la universalidad auténtica esté fundada en las formas "a priori", (las formas que se dan originalmente), las formas que constituyen las cosas mismas como fenómenos.

La teoría filosofal a diferencia del entendimiento, consiste en demostrar que la verdad, la idea, no se cifran en vagas generalidades sino en algo general que es, de suyo, lo particular, lo determinado.

Este mismo autor Abbagnano define la técnica, como semejante al arte y dice que es todo conjunto de reglas aptas para dirigir eficazmente una actividad cualquiera.

La técnica es un procedimiento cualquiera, regulado por normas y provisto de una determinada eficacia.

La Real Academia de la Lengua Española define la ciencia, como el conocimiento que pretende incluir en cualquier modo de medida una garantía de la propia validez y además dice, la ciencia es el conocimiento cierto de las cosas por sus principios y causas.

\section{¿Quiénes deben de participar en esta reformulación de la Docencia en Medicina?}

Todas las autoridades y profesores de la Facultad están en la necesidad de participar en este proceso.

Este proceso debe desarrollarse porque la universidad adiestra a profesionales integrales, no tecnólogos que reciben una formación de actualización práctica de instrumentos más o menos sofisticados, pero ignora los fundamentos de su funcionamiento y no están preparados para tratar con un nivel profesional integral a los pacientes. 


\section{¿Cuándo debe iniciarse este proceso y cómo?}

El cambio debe ser gradual y se debe iniciar, con la reinstauración de la enseñanza de cursos preparatorios básicos en los primeros años, tales como matemática, física, biología, filosofía, teoría del conocimiento e idiomas, literatura.

Por otro lado, se deben asignar a los grupos de práctica, un tutor que es el instructor a través de capítulos de los cursos y los alumnos deben rotar luego de períodos trimestrales; ésta la única forma en que el alumno y el profesor se compenetren entre ellos; que aprendan cuáles son los límites de las capacidades de cada uno de ellos; que conozcan de cerca la forma de estudiar y aprender; que conduzcan seminarios para ser expuestos ante la totalidad de los alumnos del salón.

Los alumnos deben de recibir como tarea, leer libros básicos de conocimiento para ser analizados y discutidos en grupo y después como ponencia ante todo el salón.

Los exámenes objetivos que se hacen en la actualidad son una farsa, que permite a los alumnos aprender a dar examen y en el resultado participan un compo- nente importante de azar, es decir de adivinanzas de responder las preguntas.

El alumno debe aprender a razonar con hilación y construir sus respuestas de una manera lógica; en otras palabras tiene que saber expresarse.

Los miembros de la Universidad necesitan conocer sus antecedentes históricos para compenetrarse con ésta. Es difícil que alguien ame una institución, una persona sino la conoce; y si es a cabalidad mejor todavía.

Las Facultades de Medicina gradúan a médicos cirujanos, los que en el mercado de trabajo no tienen ninguna posibilidad de obtener empleo; se propone que a partir del penúltimo año de medicina, el alumno tome la decisión de ejercer como especialista en alguna rama más o menos sofisticada o haga una extensión de dos años, rotando por las cuatro grandes ramas de la clínica: Medicina, Pediatría, Cirugía y Gine-Obstetricia a fin de lograr el título de Médico de Familia.

El énfasis de las Facultades de Medicina debe graduar especialistas en atención primaria que es lo que más necesita la sociedad. 